\title{
University Rankings as a Tool for Assessing the Quality of Education in the Context of Globalization
}

\author{
Nikita Avralev ${ }^{1} \&$ Irina Efimova ${ }^{2}$ \\ ${ }^{1}$ Public Relations, Rector's Office, Lobachevsky State University of Nizhni Novgorod, Nizhni Novgorod, \\ Russian Federation \\ ${ }^{2}$ Public Relations and Mass Media Department, Lobachevsky State University of Nizhni Novgorod, Nizhni \\ Novgorod, Russian Federation \\ Correspondence: Nikita Avralev, Lobachevsky State University of Nizhni Novgorod, Nizhni Novgorod, Russian \\ Federation. E-mail: pr@unn.ru
}

Received: December 22, 2014 Accepted: January 28, 2015 Online Published: April 20, 2015

doi:10.5539/ass.v11n10p292 URL: http://dx.doi.org/10.5539/ass.v11n10p292

\begin{abstract}
Article is devoted to the new conditions for the development of society characterized by the reconstruction of the higher education and problem of increasing the competitiveness of Russian universities in the world. Global university rankings today are becoming indicators of the implementation of the integration process and competitive tool in the context of globalization of higher education. A characteristic feature of modern development is the transition to a new stage of the formation of an innovative society, to build an economy based on the generation, distribution, transfer and use of knowledge. Ability to adapt capacity to the constantly changing environment is becoming the leading trend, the main source of material prosperity of civil society. And university rankings as indicators and tools of the competitiveness of universities certainly play an increasingly important role in the interaction of universities, businesses and states in the global educational space.

Modern period of development in Russia clearly identified the need to update the main priorities in the field of education in line with global trends. One such leading priority, as the quality of education found expression in national doctrine of Russian education. This circumstance is dictated by the presence of the basic contradiction between the modern requirements for quality of higher education and restrictions apply methods and technologies in the management process. Designing an effective system of quality management education is determined by a number of conditions and factors that create discomfort or provide adaptability alternatively.
\end{abstract}

Keywords: competitiveness, university rankings, quality of education, competitive tool, economy of knowledge

\section{Introduction}

The world has enough of any criteria and indicators to judge the development of a country, but to see the perspective necessary to pay more attention to the fundamental sources of development and primarily education. Without education is a meaningless argument about human capital. In the 21 st century people need to get new skills, knowledge and skills than in the past, and that the modern education system must meet these requirements. Globalization of Higher Education is the most important part of the global innovation economy (Avralev \& Efimova, 2013) and educational and research functions of universities is increasingly becoming a critical link in global innovation linkages. Today, the effectiveness of the integration of education, science and business to a large extent depend on the prospects for socio-economic development, competitiveness and effectiveness of responses to the new challenges of the global economy.

One of the main mechanisms for promoting higher education institutions in the rankings is to integrate the resources, talents and motivated young people aimed at the result. Log in this kind of world scientific and educational society, which creates recognized universities of the world. International practice shows the increase of competitiveness, it is necessary to create a set of strategic initiatives of the world's leading centers, although it is not the fruit of a large but close-knit team. (Chuprunov et al., 2010)

Implementation of quality management at all levels ensures the continuity of the process, as at certain stages of its implemented and target priorities and resources, software and technological support, and monitoring results.

Designing an effective system of quality management education is determined by a number of conditions and 
factors that create discomfort or, conversely, to ensure adaptability.

Analysis of the problem clearly indicates the reasons of its origin in the new socio-cultural environment of our community. This crisis of former systems of values and priorities, the formation of a new philosophy of society built on human and national values; development priorities and regionalization, municipalization of education systems; increased stratification processes. (Rykhtik \& Krivov, 2015) And in this regard, the development of the education market, the uneven development of the socio-economic conditions, as well as the division of society into rich and poor; revitalization of regional denominations and the revival of spiritual life; development of management theory and practice based on the achievements of management and marketing, the emergence and implementation of international quality standards, the transition to the development of educational systems and progressive model of education and technology, etc. All of these reasons, no doubt, are prerequisites for giving sufficient grounds to find effective mechanisms for quality management. (Avralev, 2013)

\section{Materials and Methods}

Quality of education, it is the result of the following components: the needs of the individual and society, target priorities, the predicted process and outcome. System-start with, no doubt, will need. They, being aware yet, conscious, give rise to a motive, and then based on the principle of free choice of form priorities and direction of both the individual and society. All these components come to the feedback or interaction between different subunits control. Thus, we can talk about the system of quality management education. At the same time, the educational process is the main process in the education system, the result of its fundamental acts education graduates. From the standpoint of standards, a measure of a person to achieve a certain level of development of properties and structures that meet the needs of any individual.

Revealed patterns of quality management system of education present their requirements throughout the system of management and are reflected in the content, principles, functions, forms and methods of management. (Avralev \& Efimova, 2013)

Modern period of Russia clearly identified the need to update the main priorities in the field of education in line with global trends. One such leading priority, as the quality of education found expression in national doctrine of Russian education. This circumstance is dictated by the presence of the basic contradiction between the modern requirements for quality of education provided by educational institutions and restrictions apply methods and technologies in the management process.

We analyze the criteria that define today start to search for a new model of education:

1) Calling the Internet and digital technology enables the emergence of new models of creation, preservation and transmission of knowledge.

2) Technological start-ups in education. Today, the leading venture capital funds in the world have recognized that online education is the "next big think", than it was online commerce in the early 2000 . This means that a new market for technology start-ups creates a new face of education in which there is no place traditional institutions, because it solves the same tasks faster and more efficiently.

3) Hyper competition and rapid development of industries. The global war for talent leads to the requirement for training formats, maximum flexibility and the development of above-professional competencies, training and superfast point competence. That is, cook 6 years specialist for a specific task is criminal. If one can prepare the same quality for 3 years, why keep it for 6 years. A number of new technologies allow doing it.

4) Call of the consumer society is a very serious challenge. The desire of the consumer society is to the relief of life and leads automatically to its reluctance to do something. If you can get the service by pressing a button, you cannot think about competence in something. In fact, education today, it is the socio-designed to support the development process on the cycle of human life from birth to death.

For many universities around the world are not so important what place they occupy in the global rankings, and it is important to place them in the national rankings of universities. Universities are not a plant for the production of robots; each graduate has their social status, their customs, etc. You can do research, but we should not forget about the level of training of graduates. Effective interaction of science and education should provide the business structure with new knowledge and highly qualified personnel. Integration of education, science and business today is the most important factor for innovative development of the country. The need for a sharp increase in innovative activity is determined by the miserable situation of the Russian Federation in this area, compared to the position of world leader. We are in the initial stages of formation of the innovation system. (Downing, 2011) 
Different countries have built their approaches to improving the competitiveness of their universities. Society and the state gradually realized a new stage of its integration into the global system of universities. We have to take the best features, best practices, while preserving their national identity of our universities. It is necessary to give universities autonomy in choosing breakthrough mechanisms for entry into the world's global rankings.

We believe that the ranking projects are an excellent initiative that mobilizes universities, forcing them to take another look at you, to test their capabilities, determine what criteria are presented strongly and which require further development. We must proceed from the mission of the University, and rankings should only help us in this. And world-class university, it is primarily that university graduates are recognizable in the world, the study of which is of interest at international conferences in most countries. (Altbach \& Salmi, 2012)

\section{Results}

As part of this research was conducted to identify the motivation of students in choosing a higher education institution, specifically Lobachevsky State University of Nizhni Novgorod (University of Nizhni Novgorod, UNN) for the years 2011-2014. The study was conducted with the help of the working tools like profile. To this questionnaire by 753 to 1,304 respondents answered. The research was conducted in the selection committees of 14 faculties and institutes of the university from June 20 to July 20 in 2011-2014 years.

General population in our research was the number of students who applied to the UNN 2011-2014 years is about 3,700 people each year. The sample size calculated by using traditional statistical methods was:

$$
n=\frac{t^{2} * \delta^{2} * N}{t^{2} * \delta^{2}+\Delta^{2} * N}
$$

where $\mathrm{n}$ - the amount of the general population

$\delta$ - the dispersion of the studied trait

$\Delta$ - set limit sampling error

$\mathrm{t}$ - confidence

$$
n=\frac{3^{2} * 1^{2} * 3700}{3^{2} * 1^{2}+0.1^{2} * 3700}=\frac{33300}{43} \approx 724 \text { people }
$$

Thus, the representativeness of the sample is to be achieved through a research of at least 724 students. Due to the certain time limitations and heterogeneity of stream entrants sample size ranged from 753 to 1,304 respondents, which satisfies the minimum value required to achieve representativeness.

Table 1. Selection of UNN applicants in 2011-2014 years

\begin{tabular}{lllcc}
\hline Year & 2011 & 2012 & 2013 & 2014 \\
\hline Number & 753 & 892 & 1304 & 883 \\
\hline
\end{tabular}

In this study, applicants were asked a series of questions regarding their awareness of the world rankings of universities and the importance of ranking performance when choosing the university for education. Results of their replies are below.

Table 2. Awareness of students of Russian and world rankings

\begin{tabular}{llll}
\hline Year & I know, it is important & I know, but do not attach importance & I've never heard \\
\hline 2011 & $38,30 \%$ & $20,50 \%$ & $41,20 \%$ \\
2012 & $39,70 \%$ & $21,40 \%$ & $38,90 \%$ \\
2013 & $42,30 \%$ & $27,90 \%$ & $29,80 \%$ \\
2014 & $41,50 \%$ & $32,30 \%$ & $26,20 \%$ \\
\hline
\end{tabular}


As we can see from the table above, the majority of respondents have information about the rankings, although it should be noted that there is a tendency to increase the number of students who have heard of the ranking (in the amount of 1 and 2 responses) from $61.1 \%$ in 2012 to $73.8 \%$ in 2014 . This trend illustrates the growing interest of students to the university rankings, so you need to continue to work to educate students, future students about university rankings, so they can see where the institution in which they are going to do, any of its ranking compared to the other, etc.

Table 3. Comparative analysis of the importance of ranking positions for high school students

\begin{tabular}{llll}
\hline Year & Yes, it affected my choice & No, it does not affect the choice of institution & It is difficult to answer \\
\hline 2011 & $55,10 \%$ & $19,80 \%$ & $25,10 \%$ \\
2012 & $59,7 \%$ & $29,50 \%$ & $10,80 \%$ \\
2013 & $53,20 \%$ & $28,60 \%$ & $18,20 \%$ \\
2014 & $69,50 \%$ & $20,30 \%$ & $10,20 \%$ \\
\hline
\end{tabular}

Comparative analysis shows that the majority of respondents ranking the university is an important indicator.

Table 4. Awareness of applicants to join UNN in the top-700 QS World University Rankings

\begin{tabular}{llll}
\hline Year & Yes, it affected my choice & Yes, but it did not affect my choice & I've never heard \\
\hline 2011 & $15,30 \%$ & $24,80 \%$ & $59,90 \%$ \\
2012 & $24,20 \%$ & $27,80 \%$ & $48,00 \%$ \\
2013 & $25,20 \%$ & $28,60 \%$ & $46,20 \%$ \\
2014 & $37,60 \%$ & $42,40 \%$ & $20,00 \%$ \\
\hline
\end{tabular}

Comparative analysis of 2011-2014, shows that if in 2011, majority of respondents (59,9\% of applicants) first learned about this ranking, then in 2014, only one in the 5th respondent answered that first hears about the QS World University Rankings.

In the global market of educational services research and development of Russian universities have become centers of Russia's integration into international networks of knowledge and technology, training centers of the most talented graduates of Russian schools and foreign program competitive with the world's leading universities, international leader in the research and development; centers converting the results of fundamental and applied research in the modernization of the country; platforms forming alumni professionals international level etc. (Rauhvargers, 2013)

Subject of rankings recently gained immense popularity. Today rankings built around a kind of business. Due to successful rankings advertised universities attract the best professors, the strongest prospective students. We can cite as an example Shanghai University. Unfortunately, none of us could think of winners and recalculate cited scientists in high school and on the basis of these data to build your ranking. And it is possible in China. Around Shanghai rankings already established cooperation of scientists, published articles, published monographs, annual conferences and academic community of the world plunged into this perspective. We analyze the risks of such activities as rankings. All of them, at least three of the most recognized Academic Ranking of World Universities (ARWU), QS World University Rankings and The Times Higher Education World University Rankings, focused on studies on the evaluation of research universities. These institutions by rankings fight for more research budgets, contracts, grants to public or private programs. If the university is in a good position in the world rankings, you may qualify for additional funding from the budget. And if it is done as opposed to educational activities, education itself will suffer. Often it turns into a virtual plane, increasing the slope is on remote technology and the usual classroom training virtually ceased to exist. No coincidence that the European Union launched its project "U-Multirank". He felt that with the global rankings something wrong, do not all move toward the implementation of the model of research universities, we cannot forget about the classical education. Attempts to reflect this in the ranking to its results not only made decisions on the allocation of budgets to universities, but families can navigate where to send their children to study. (Efimova, 2013)

In higher education, the Government of our country's course aims to integrate the universities in the world educational space. Now in our country about 100 thousand foreign students, and that this number increased, it is 
necessary that universities have increased their attractiveness in the global higher education market. And in order to raise their international competitiveness, it is necessary to use multiple tools. And the Russian government now considers the Program "5-100-2020" one of the basic tools. This program is a serious public investment aimed at improving international competitiveness. Also, the Government approved the establishment ranking of universities and colleges of the BRICS (Brazil, Russia, India, China, South Africa) countries, CIS (Commonwealth of Independent States) countries plus Georgia, Latvia, Lithuania and Estonia. All dialogues about rankings of universities in these countries are based on a voluntary agreement on the benefits of competing universities, enhancing mobility, vacancy in international exchanges. And it is in this context that the ratings are the marketing tools in the educational market in comparable universities in a competitive impact on the economy of these countries. And another scale, the ratings are very difficult to imagine. Rankings as a litmus test, help us to see with whom, what we loosely integrate universities, and with whom, you need a different approach, a different indicator. Universities need to see where they are, who are stronger and we need to do to get ahead, to become competitive and visible in the world community.

\section{Discussion}

Today, throughout the world there is a tendency to move from bilateral cooperation of individual universities within specific educational or research programs to multilateral interaction consortia of universities widely formulated problems and issues.

The emergence of this trend due to the fact that more and more scientific problems require cooperation among scientists from different countries, and with the fact that the aim of modern educational programs becomes training with the skills and experience of interaction with native cultures and the maximum amount demanded in the global market.

The main task in the field of higher education is to make it competitive on the world stage by creating a balanced and has its own specific differentiated structure, involving the development of research universities are generalists, and educational research universities, universities own definition of the level and specificity, as well as improve management policies, including by strengthening the mechanisms of competition and the distribution of funds. (Weber \& Duderstadt, 2012)

As the decisive conditions for the implementation of reforms in the field of science and education focuses on three points:

- Loosening of central government control and giving autonomy to universities in the field of teaching and learning activities, research, technological development and services;

- A new system of recruitment to universities with different types of tests in addition to the exam;

- Improving the quality of education.

To this end, the Russian side should clearly define their interests in the creation of any joint scientific and educational projects, to develop mutually beneficial doctrine which translated to fierce rivalry between our countries in the educational space in milder variants co-development.

Today we must think about how to increase the capacity of the university, how to attract good professors, while realizing that behind their Russian scientists struggle is very large, so it is necessary to expand the geographic scope of the search of world-class specialists.

Higher education embraced the concept of sustainability early though it took many years for passion and beliefs to translate into focus and action. The world's universities have a compelling responsibility to be at the forefront, breaking down barriers, taking risks and modeling sustainability.

Universities are uniquely situated to take this leadership role, and, in fact, no other entity or system may have the ability, capacity and positioning to do so. A university culture of sustainability fuels the principles, practices and economies of sustainability, while being reinforced by them.

From a national perspective, one can say that the increased competition has induced a process of differentiation across universities in many member countries. Some universities are on the way to become truly internationally oriented, research-based universities while other ones are developing their strengths in a national or regional context; others are focusing on their role as teaching institutions. One must be clear about this process of differentiation: the procedure is not easy, as it raises various difficult and sometimes painful issues. But it opens the perspective for a highly competitive and successful system of higher education and research that can support the efforts to achieve and maintain global sustainability.

Universities, thanks rankings begin to analyze their position among other universities, start looking for your 
weaknesses and seek mechanisms for their requalification strong. And to get into the global space, we need to improve communication with employers to find ways how to inspire the academic community to participate in the polls, how to improve the publication activity, how to create a website so that experts in ranking field had no issues with data verification, etc. (Weber \& Duderstadt, 2006)

\section{Conclusion}

We will constantly speak, what we need rating on areas of expertise in the field, the program, how to deal with the social and cultural functions of universities, but we need to understand exactly what we need rankings and what they need to do. And it's a good tool to compare themselves and their kind in the country, at the regional level and in the world. We can consider not only the global competition, but also as a global partnership in the field of economy, finance, and now education. (Baluev, 2015) We believe that it is possible to carry out joint research, international activities, network master's programs, graduate programs, etc., that will be a productive form of interaction between universities, which ultimately give a synergistic effect. In a growing sector of distance education just need to create joint projects and programs. (Thurman \& Efimova, 2014)

The main task in the field of higher education is to make it competitive on the world stage by creating a balanced and has its own specific differentiated structure, involving the development of research universities are generalists, and educational research universities, universities own definition of the level and specificity, as well as improve management policies, including by strengthening the mechanisms of competition and the distribution of funds.

As the decisive conditions for the implementation of reforms in the field of science and education focuses on three points:

- Loosening of central government control and giving autonomy to universities in the field of teaching and learning activities, research, technological development and services;

- A new system of recruitment to universities with different types of tests in addition to the exam;

- Improving the quality of education.

Today, throughout the world there is a tendency to move from bilateral cooperation of individual universities within specific educational or research programs to multilateral interaction consortia of universities widely formulated problems and issues.

The emergence of this trend due to the fact that more and more scientific problems require cooperation among scientists from different countries, and with the fact that the aim of modern educational programs becomes training with the skills and experience of interaction with native cultures and the maximum amount demanded in the global market.

Today we have to think how to improve the potential of high school, how to attract good professors, while realizing that behind their Russian scientists struggle is very large, so it is necessary to expand the geographic scope of the search of world-class specialists.

Communication and collaboration in order to create a capsule model to date are the main mechanisms in the promotion of higher education institutions in the world space.

We must clearly understand that we can get from the collaboration. We must increase the rate of citing including through joint work within the overall research.

Mobility of scientists should be considered as one of the key factors for the competitiveness of universities and the development of the country as a whole. Second, no less important, is the international collaboration, namely articles written in international collaborations have the effect of 3-4 times more than the collaboration within the country. It is necessary to maintain and increase their PR universities to form a stable image of the university, do not forget about the further development of the educational system. These are the basic steps for the real development of science and education of any university. The international community must show its attractiveness, competitiveness, it is necessary to enter the international level, to become the best.

Our quality of life, the development of production and the level of the country's economy depends on high technology. Therefore, it is important to invest in science to maintain and develop the system of scientific discoveries.

\section{References}

Altbach, P., \& Salmi, D. (2012). The Road to Academic Excellence. The Making of World-Class Research Universities. The whole world (p. 410). Moscow. http://dx.doi.org/10.1596/978-0-8213-8952-2 
Avralev, N. (2013). The Process of Merging Universities as One of the Key Tools to Improve Their Competitiveness and Strengthen the Rating Positions in the Global Market of Educational Services. World Applied Sciences Journal, 25(9), 1378-1382.

Avralev, N., \& Efimova I. (2013). University Rankings as a Tool to Enhance Competitiveness, Clustering and Transnational Governance of Higher Education in the Context of Globalization. Middle-East Journal of Scientific Research, 16(3), 357-361.

Avralev, N., \& Efimova, I. (2013). The Role of the International University Network Organizations in the Innovative Development of Russia. Middle-East Journal of Scientific Research, 14(10), 1277-1291.

Baluev, D. G. (2015) Shifts in the Meaning of Sovereignty and Applicability of the Concept for Analysis of Contemporary World Politics. Asian Social Science, 11(3), 212-217.

Chuprunov, E. V., Gurbatov, S. N., \& Bednyy, B. I. (2010). Comprehensive Research University in the Innovative Knowledge Society. University Management: Practice and Analysis, 1, 6-16.

Downing, K. (2011). In M. Stiasny, \& T. Gore (Eds.), Do rankings drive global aspirations at the expense of regional development' in Going Global: Reflections on the landscape for policy makers and practitioners in tertiary education (p. 230). Emerald, Bingley, United Kingdom.

Efimova, I. (2013). Rankings as Tools to Promote Global Education Market. World Applied Sciences Journal, 25(10), 1400-1404.

Rauhvargers, A. (2013). Global university rankings and their impact report II (pp. 78-81). Brussels: The European University Association.

Rykhtik, M. I., \& Krivov, S. V. (2015). Western European Immigration Policy: Implications and Lessons for Russia. Asian Social Science, 11(3), 249-254.

Thurman, P. W., \& Efimova, I. (2014). Use of rankings to improve global competitiveness of Russian's higher education institutions and technology exports. Life Sci J, 11(11), 285-289.

Weber, L., \& Duderstadt, J. (2006). Universities and Business: Partnering for the Knowledge Society. Economica, 113-116. Ltd, France.

Weber, L., \& Duderstadt, J. (2012). Global Sustainability and the Responsibilities of Universities. Economica, 150-152. Ltd, France.

\section{Copyrights}

Copyright for this article is retained by the author(s), with first publication rights granted to the journal.

This is an open-access article distributed under the terms and conditions of the Creative Commons Attribution license (http://creativecommons.org/licenses/by/3.0/). 